\title{
O GARANTISMO E A INGERÊNCIA DO ESTADO NA ADMINISTRAÇÃO DOS BENS TEMPORAIS DA IGREJA CATÓLICA E DE ASSOCIAÇÕES RELIGIOSAS: UM ESTUDO DE CASO
}

\author{
[Guarantee and state interference in the administration of the temporal \\ goods of the Catholic Church and religious associations: a case study]
}

FRANCISCO JUNIOR DE OLIVEIRA MARQUES ${ }^{1}$

NESTOR EDUARDO ARARUNA SANTIAGO ${ }^{2}$

\begin{abstract}
Resumo
O presente artigo tem como objetivo analisar a intervenção estatal na administração dos bens temporais de associações civis com fins religiosos e entidades religiosas católicas a partir de uma visão garantista. O Ministério Público de Goiás (MPGO) realizou uma investigação na Diocese de Formosa em 2018, e na Associação Filhos do Pai Eterno (AFIPE), em 2020. Nas operações do MPGO, denominadas Caifás e Vendilhões, investigaram-se diversas suspeitas de condutas ilícitas, relacionando aquelas entidades com organizações criminosas. O texto enfoca a relação entre o garantismo e a atuação do MPGO nessas operações, reafirmando o papel do Estado constitucional de direito que tende a constituir uma forma de governo das leis, no qual os poderes públicos são regulados e limitados pelo direito em função da tutela dos indivíduos e das entidades privadas. Daqui emerge a pergunta: a atuação do MPGO obedeceu aos cânones garantistas, sob o ponto de vista dos axiomas desenvolvidos por Luigi Ferrajoli? A metodologia é bibliográfica, documental, de caráter explicativo, qualitativa e de natureza teórica. Os resultados obtidos levam a concluir que o MPGO não respeitou os direitos fundamentais das entidades, lesando acordos internacionais, princípios constitucionais e o ordenamento jurídico estatutário.
\end{abstract}

Palavras-chaves: Bens eclesiásticos, Igreja Católica, garantismo, Ministério Público, Direito canônico.

\begin{abstract}
Resumen
El presente artículo se propone analizar la intervención estatal en la administración de los bienes temporales de asociaciones civiles con fines religiosos y de entidades religiosas católicas desde una visión garantista. El Ministerio Público de Goiás (MPGO) realizó una investigación en la Diócesis de Formosa en 2018, y en la Asociación Hijos del Padre Eterno (AFIPE), en 2020. En las operaciones del MPGO, denominadas Caifás y Vendilhões, se investigaron varias sospechas de conductas ilícitas, relacionando esas entidades con organizaciones criminales. El texto se detiene en la relación entre el garantismo y la actuación del MPGO en esas operaciones, reafirmando el papel del Estado
\end{abstract}

\footnotetext{
${ }^{1}$ Doutor, Mestre e Especialista em Direito (UFMG, Brasil), com estágio pós-doutoral (Universidade do Minho, Portugal). Professor Titular da Universidade de Fortaleza (Doutorado, Mestrado, Especializações e Graduação em Direito). Professor Adjunto da Universidade Federal do Ceará (Curso de Graduação em Direito). Advogado criminalista. E-mail: nestorsantiago@unifor.br

${ }_{2}^{2}$ Mestre em teologia (Faculdade dos Jesuitas, Belo Horizonte, Brasil) e Doutorando em Direito Constitucional pelo Programa de Pós-Graduação da Universidade de Fortaleza. E-mail: sssmarquez@hotmail.com.
} 
Francisco Junior De Oliveira Marques \& Nestor Eduardo Araruna Santiago: O garantismo e a ingerência do Estado na administração dos bens temporais da igreja católica e de associações religiosas: um estudo de caso

constitucional de derecho que tiende a constituir una forma de gobierno de las leyes, en la que los poderes públicos están regulados y limitados por la ley para proteger a los individuos y a las entidades privadas. De aquí surge la pregunta: ¿el ejercicio del MPGO siguió los cánones garantistas, desde el punto de vista de los axiomas desarrollados por Luigi Ferrajoli? La metodología es bibliográfica, documental, de carácter explicativo, cualitativo y de naturaleza teórica. Los resultados obtenidos permiten concluir que el MPGO no ha respetado los fundamentos garantistas del Estado constitucional, perjudicando acuerdos internacionales, principios constitucionales y el ordenamiento jurídico estatutario.

Palabras clave: Bienes eclesiásticos, Iglesia católica, garantismo, Ministerio público, Derecho canónico.

DOI: $10.7764 / R L D R .11 .136$

\section{INTRODUÇÃO}

A administração econômica do patrimônio temporal das entidades religiosas católicas é tutelada por um corpus jurídico específico, que define a natureza dos bens eclesiásticos, nos termos do ordenamento canônico, dos tratados internacionais e dos princípios constitucionais que garantem a sua melhor governança. As associações, ainda que de fins religiosos, têm natureza jurídica diversa das entidades religiosas, originando-se da legislação civilista pátria.

Todas essas nuanças exigem um conhecimento das regras jurídicas que regem a administração dos bens eclesiásticos e das associações civis, a fim de verificar os possíveis ilícitos e definir a competência para procedimentos investigatórios legítimos. Exatamente neste contexto, emergem os cânones garantistas desenvolvidos por Luigi Ferrajoli como critérios essenciais para limitar o poder estatal no seu agir repressivo e de controle aos direitos individuais e associativos.

O conjunto de normas produzidas pelo Estado de Direito, e por ele controlado nos limites constitucionais, tem o fundamental objetivo de assegurar dignidade e liberdade às pessoas concretas, como aplicação da teoria do garantismo aos direitos individuais. Da 
Francisco Junior De Oliveira Marques \& Nestor Eduardo Araruna Santiago: O garantismo e a ingerência do Estado na administração dos bens temporais da igreja católica e de associações religiosas: um estudo de caso

mesma forma, à medida que o direito penal e o poder punitivo tem sido aplicado às organizações em razão dos crimes corporativos, exige-se, proporcionalmente, a proteção dos cânones garantistas aos direitos fundamentais dessas instituições e de seus representantes legais.

Portanto, o Estado Constitucional de Direito tende a constituir uma forma de governo das leis, no qual os poderes públicos são regulados e limitados pelo direito estabelecido em função da tutela dos direitos fundamentais. No caso das entidades e associações religiosas católicas, a atividade estatal deve seguir os direitos estabelecidos no plano constitucional, infraconstitucional e internacional-canônico que emolduram os direitos fundamentais dessas entidades.

A moldura do Estado constitucional de direito garante o princípio da laicidade e colabora para que se realizem às finalidades próprias dessas entidades para preservação do interesse público. Além de cooperador, o Estado também é censor, na medida em que se observem irregularidades na operação de entidades não laicas. Nos últimos vinte anos as organizações religiosas têm sido colocadas sob suspeita em razão de investigações que sugerem conexão entre igrejas e/ou líderes religiosos com atividades financeiras ilícitas.

Em uma investigação de um ano da rede composta pela Columbia Journalism Investigations (CJI) e o Centro Latinoamericano de Investigación Periodistica, realizou-se um relatório denominado Paraiso de Dinero y Fe (2020), sobre crime organizado e corrupção de igrejas e seus líderes no continente americano. O fenômeno criminoso, refletido na base de dados, atesta que algumas instituições religiosas foram usadas repetidamente para lavagem de dinheiro, apropriação indébita, crime organizado, dentre outros crimes.

É neste ambiente de suspeita que as operações Caifás (2018) e Vendilhões (2020) do Ministério Público de Goiás (MPGO) se situam, intervindo e promovendo investigações contra entidades e associações religiosas católicas. O estudo de casos das operações, que 
Francisco Junior De Oliveira Marques \& Nestor Eduardo Araruna Santiago: O garantismo e a ingerência do Estado na administração dos bens temporais da igreja católica e de associações religiosas: um estudo de caso

ganharam grade notoriedade midiática, são emblemáticos. Na primeira, o MPGO acusa o bispo diocesano de Formosa (GO) e cúmplices por desvio de valores e organização criminosa; já na segunda, acusa-se o padre fundador-presidente da Associação do Pai Eterno (AFIPE) por suposta organização criminosa, apropriação indébita, lavagem de dinheiro, falsificação de documentos e sonegação fiscal.

O objetivo da presente pesquisa é analisar a intervenção ministerial na administração dos bens temporais de associações e entidades religiosas católicas, avaliando se sua ação está em obediência aos cânones garantistas, sob o ponto de vista dos axiomas desenvolvidos por Luigi Ferrajoli. A metodologia é bibliográfica, elaborada a partir de material publicado em livros, revistas e pesquisa em bases eletrônicas; bem como documental, mediante consulta a legislação e estudo de casos. Quanto aos objetivos, a pesquisa é explicativa, pois identifica e analisa a atuação o MPGO quanto a administração de bens eclesiásticos e associações religiosas segundo a perspectiva garantista de Ferrajoli. Quanto à abordagem ao problema apresentado, faz-se uma pesquisa qualitativa mediante o estudo de casos, especificamente, das operações do MPGO denominadas Caifás e Vendilhões.

O percurso da pesquisa iniciará com o estudo da evolução do conceito de garantismo até sua formulação ferrajoliana. No item seguinte, será apresentado o direito garantista penal de Ferrajoli e sua aplicação às pessoas jurídicas, especialmente, às entidades religiosas e associações civis. Finalmente, o último item da pesquisa, tratará da atuação do Ministério Público nas operações Caifás e Vendilhões e sua coerência garantista nos casos. Os resultados obtidos levam a concluir que o Estado não respeitou os direitos fundamentais das entidades, lesando acordos internacionais, princípios constitucionais e o ordenamento jurídico estatutário.

\section{GARANTISMO: EVOLUÇÃO DO CONCEITO E PARADIGMA DO ESTADO DEMOCARTICO-CONSTITUCIONAL DE FERRAJOLI}


Francisco Junior De Oliveira Marques \& Nestor Eduardo Araruna Santiago: O garantismo e a ingerência do Estado na administração dos bens temporais da igreja católica e de associações religiosas: um estudo de caso

O conceito de garantismo tem sua primeira formulação no século XIX, com a obra de Charles Fourier, Le nouveau monde industriel et sociétaire, de 1829. Ippolito (2011, p. 54), ao estudar a evolução do conceito, faz notar que Fourier usa o garantismo para indicar uma etapa da evolução social em direção à harmonia da sociedade ${ }^{3}$. O garantismo é, neste modelo, um sistema de segurança social que protege os mais frágeis, possibilitando-os garantias seja na esfera pública ou privada. Fourier afirma que a civilização apenas alcançará justiça, ainda que num sistema representativo, quando estiver sob as bases do garantismo como lugar do progresso real, em que a propriedade satisfará todas as classes ${ }^{4}$.

Nessa inspiração fourieriana emerge o garantismo social, que tem na obra de Paul Jouvencel, Du droit de vivre, de proprieté et du garatisme (1829), uma representação concreta. Jouvencel descreve a civilização de seu tempo como a sociedade da concorrência, na qual suas lutas são solitárias ${ }^{5}$. Nesse sentido, garantir significa associar a humanidade e afastar todo tipo de individualismo e isolacionismo a fim de combater o absoluto mal-estar material, ou seja, a fome e a ignorância.

Para Jouvencel, o sistema garantista deve assegurar trabalho, educação, pensão às pessoas idosas etc ${ }^{6}$. E tudo isso depende da iniciativa do governo que tem a responsabilidade de concretizar o sistema sob a base da fraternidade ou solidariedade. Esse tipo de garantismo tem sua última e mais evoluída fronteira no Estado de bem-estar social do início do século XX. Em determinadas regiões da Europa pode-se falar de hiper-garantismo seletivo, que assegura diferentes direitos sociais em vista do princípio da igualdade de direitos e oportunidades ${ }^{7}$.

\footnotetext{
${ }^{3}$ Ippolito, D. Itinerari del garantismo. Em: Videre, 2011, a. 3, n. 6, p. 54.

${ }^{4}$ Fourier, C. Le nouveau monde industriel et sociétaire, 1829, p. 142.

${ }^{5}$ Jouvencel, P. Droit du vivre de la proprieté e du garantisme. Paris, Paul Masgana, 1847, p. 57.

${ }^{6}$ Id.Ibid., pp. 59-65.

${ }^{7}$ Ferrera, M. Il modelo sud-europeo di walfare state. Em: Revista Italiana de Scienza Política, 1996, Vol. 36, n. 1, pp. 67-101.
} 
Francisco Junior De Oliveira Marques \& Nestor Eduardo Araruna Santiago: O garantismo e a ingerência do Estado na administração dos bens temporais da igreja católica e de associações religiosas: um estudo de caso

Paralelamente a essa ideia clássica de garantismo, Guido de Ruggiero, na sua obra Storia del liberalismo in Europa (1925) pensa o conceito como sistema que assegura liberdade ao indivíduo frente ao Estado. De Ruggiero entende que o liberalismo foi a doutrina por excelência da civilização ocidental e o produto ideológico do poder burguês que levou a Europa a profundas mudanças socioeconômicas ${ }^{8}$. No centro do liberalismo, a liberdade é uma construção social que exige princípios garantistas. Nessa perspectiva, o garantismo vai centrar-se nas garantias constitucionais das liberdades fundamentais e tornar-se o componente essencial do constitucionalismo moderno ${ }^{9}$.

Na perspectiva da relação entre liberdade e autoridade, o garantismo se reveste da teoria liberal do direito penal, de matriz iluminista e que resultou na constituição do direito penal mínimo. Essa combinação contemporânea de garantismo e direito penal tem sua proto-história no século XVIII, na figura de Mario Pagano (1748), para quem o garantismo penal é uma doutrina da limitação da discricionariedade do poder do juiz ${ }^{10}$. Devedor do pensamento iluminista de Montesquieu, Pagano faz emergir a consciência sobre a importância constitucional da legislação penal ${ }^{11}$ e, igualmente, a perspectiva de Rousseau e Kant, na qual a sociedade deveria regular-se a partir de instituições que se fundam na razão e não na arbitrariedade do poder. Assim, a essência das normas se encontra na análise de seu conteúdo, seus elementos e na tutela que instituía determinados interesses.

Numa ulterior etapa de sua evolução, segundo Ippolito ${ }^{12}$, o conceito de garantismo assume toda sua significação contemporânea à luz da legislação emergencial italiana contra o terrorismo da década de 1970. A doutrina jurídica progressista, num contexto de restrições e legalismo punitivo do Estado, reafirma o primado dos direitos individuais e da liberdade frente ao poder estatal.

\footnotetext{
${ }^{8}$ De Reggiero, G. Historia del liberalismo europeo. Albolte, Editorial Comares, 2005.

${ }^{9}$ Broglio, C.-M. Bobbio e Matteucci su constituzionalismo e positivismo giuridico. Con una lettera di Noberto Bobbio a Nicola Mateucci. Em: Materiali Per Una Storia della Cultura Giuridica, a. 30, n. 2, 2000, pp. 387-425,

10 Pagano, M. Considerazioni sul processo criminale. Napoli, Tosi y Nobile, 1801, p. 21.

${ }^{11}$ Ippolito, D. Itinerari del garantismo. Op. Cit., p. 529

12 Id.Ibid., pp. 55-57.
} 
Francisco Junior De Oliveira Marques \& Nestor Eduardo Araruna Santiago: O garantismo e a ingerência do Estado na administração dos bens temporais da igreja católica e de associações religiosas: um estudo de caso

A consolidação do termo garantismo, numa perspectiva político-jurídica contemporânea, se dá mediante a atividade da magistratura e pesquisa cientifica de Luigi Ferrajoli (1940). Corroborando com o sitz in leben do conceito apresentado acima, Ferrajoli recorda que a palavra garantismo se renova no léxico jurídico, introduzida no direito penal italiano nos anos $1970^{13}$. Aqui, garantismo torna-se o nome da teoria liberal do direito penal ou direito penal mínimo.

A difusão desse pensamento dá-se pela obra de Ferrajoli, Diritto e Ragione: teoria del garantismo penale (1989). No prefacio do livro, Norberto Bobbio esclarece que o objetivo de Ferrajoli é elaborar a relação entre liberdade e poder, apresentando os fundamentos do Estado de direito, cuja finalidade é a tutela das liberdades dos cidadãos frente ao poder punitivo do Estado. Nesse sentido, Zaffaroni ${ }^{14}$ escreve que a obra ferrajoliana repropõe o direito penal liberal com uma refinada abordagem.

Para além dessa perspectiva que relaciona garantismo com direito penal e, de fato, sistematiza uma sólida filosofia da justiça penal, a obra de Ferrajoli pretende ser uma teoria do Estado democrático-constitucional. Nessa leitura mais ampla da obra ferrajoliana, o garanismo penal é situado apenas numa parte de sua produção científica, apesar de ser, nos termos de Ippolito ${ }^{15}$, historicamente mais antiga por fundar-se na tradição iluminista montesquiana e, culturalmente mais conhecida, por ser a perspectiva garantista mais difundida. De fato, o garantismo estende-se a todo sistema de proteção dos direitos fundamentais, na medida que garantismo é sinônimo de Estado constitucional de direito.

\footnotetext{
${ }^{13}$ G. Pisarello, R. Suriano. Entrevista a Luigi Ferrajoli. Isonomía. Em: Revista de Teoría e Filosofia del Derecho, n. 9, 1998.

${ }^{14}$ Zaffaroni, E.-R. La rinascita del diritto penale liberale o la Croce Rossa giudiziaria. Em: Gianformaggio, L. (org.) Le ragioni del garantismo: discutendo con Luigi Ferrajoli. Torino, Giappichelli Editore, 1993, p. 383.

${ }^{15}$ Ippolito, D. Itinerari del garantismo. Op. Cit., pp. 62-63.
} 
Francisco Junior De Oliveira Marques \& Nestor Eduardo Araruna Santiago: O garantismo e a ingerência do Estado na administração dos bens temporais da igreja católica e de associações religiosas: um estudo de caso

Na abordagem global da teoria garantista de Ferrajoli ${ }^{16}$ se resistetematiza o paradigma juspolítico democrático, propondo uma evolução do Estado legislativo de direito ao Estado constitucional de direito. Esses dois modelos de democracia e organização política diversas têm como objetivo realizar o ideal de governo da lei ou constituição de uma forma de Estado no qual os poderes públicos são regulados e limitados na tutela dos direitos individuais ${ }^{17}$.

O Estado legislativo de direito representa o alcance inicial da meta do governo pela lei mediante a incorporação do princípio da legalidade. O direito existente e válido é o conjunto das normas produzidas por órgãos competentes legítimos. Contudo, essa estrutura estatal não será o paradigma do Estado de direito em sentido estrito, pois a mesma lei que condiciona os poderes estatais e privados não está sob nenhum condicionamento. O Estado legislativo de direito torna-se uma autoridade absoluta, transformando-se num Estado legal, ao invés de configurar-se numa Estado de direito de forma estrita.

Essa grande mudança paradigmática do direito se expressou na superioridade do legislador, guiada pelo princípio per leges. A segunda, e mais importante, consiste na subordinação da própria lei, garantida por uma jurisdição de legalidade encarnada num texto constitucional. O Estado constitucional de direito altera o modelo precedente, como este o fez com o modelo jurisprudencial pré-moderno, em três aspectos.

Primeiramente, sob o plano da natureza do direito, a positividade se estende da lei às normas que regulam os conteúdos das leis. Essa alteração toca a teoria da validade, pois as leis já não estão apenas sujeitadas as normas formais de produção, mas também as normas substanciais de significado. As normas que tenham significados contraditórios com as normas constitucionais não são admitidas. A existência e a força (vigore) da norma, dissociadas da justiça no paradigma paleojuspositivista, são dissociadas agora também da validade, sendo possível que uma norma formalmente valida e vigente, seja

\footnotetext{
${ }^{16}$ Ferrajoli, L. Diritto fundamentali. Um dibattito teórico. 3a․ Ed. Roma-Bari, Laterza, 2008, pp. 33-34.

${ }^{17}$ Ippolito, D. Itinerari del garantismo. Op. Cit., p. 63.
} 
Francisco Junior De Oliveira Marques \& Nestor Eduardo Araruna Santiago: O garantismo e a ingerência do Estado na administração dos bens temporais da igreja católica e de associações religiosas: um estudo de caso

substancialmente inválida em razão do conflito com a norma constitucional substancial, a exemplo do princípio da igualdade ou dos direitos fundamentais. Ferrajoli ${ }^{18}$ precisa que, enquanto a norma de reconhecimento de força (vigore) preserva a mera legalidade, a norma de reconhecimento da validade (valitá) é mais complexa e integra a estrita legalidade, vinculando a lei de forma substancial, isto é, no seu conteúdo ou significado das normas produzidas, em estrita coerência com os princípios e garantias estabelecidos nas Constituições.

A segunda alteração, no plano da interpretação e aplicação, processa uma mudança no papel do juiz, seja na forma ou nas condições de sua sujeição à lei. A incorporação dos direitos e garantias fundamentais ao texto constitucional e, consequentemente, a possibilidade de normas serem inválidas por estarem em conflito com a Constituição, muda a relação entre os juízes e a lei. No modelo anterior, o que prevalecia era a sujeição à lei seja qual fosse o conteúdo ou significado; agora, a sujeição legal só é possível na medida que tenha validade constitucional. Nesse sentido, a interpretação e aplicação da lei realizada pelo juiz é um juízo constitucional à própria lei. ${ }^{19}$

Finalmente, a terceira alteração se processa no plano da ciência jurídica ou paradigma epistemológico do seu papel e objeto, que passa da simples função explicativa-avaliativa ao crítico e projetual. No antigo paradigma do Estado legislativo de direito, a crítica e a projeção do direito vigente eram possíveis apenas a partir da exterioridade, sob o plano ético-político, ou simplesmente da oportunidade ou racionalidade, não havendo espaço para vícios jurídicos substancias internos ao direito positivo, seja pela antinomia gerada da incoerência entre as normas, nem pela incompletude do sistema, ou ainda pela inexistência de vínculos constitucionais. No sistema complexo do Estado constitucional de direito que disciplina não apenas as formas da produção jurídica, mas também os significados normativos produzidos, incoerência e incompletude, antinomias e lacunas são vícios conexos às diferenças

\footnotetext{
${ }^{18}$ Ferrajoli, L. Diritto fundamentali. Um dibattito teórico. Op. Cit., p. 354.

${ }^{19}$ Id.Ibid., p. 355.
} 
Francisco Junior De Oliveira Marques \& Nestor Eduardo Araruna Santiago: O garantismo e a ingerência do Estado na administração dos bens temporais da igreja católica e de associações religiosas: um estudo de caso

normativas nas quais se articulam a sua própria estrutura formal. A constitucionalização tomada a sério, como projeção do direito a partir do próprio direito, confere à ciência jurídica e à jurisprudência, uma função e uma dimensão pragmática ${ }^{20}$.

Portanto, para Ferrajoli, à luz da alteração dos planos da natureza, interpretaçãoaplicação e epistemológico, correspondem três culturas, três modelos de direito e três noções de validade, que fundam o sistema político encarnado no Ancien Régime, no Estado legislativo de direito e no Estado constitucional de direto. Com a primeira revolução institucional, a existência e validade do direito dissocia-se da justiça, e o pacto social fundador da ordem jurídica positiva estabelece que a lei formalmente constituída deve vincular o juiz. Na segunda revolução, é a própria lei que está vinculada a princípios substanciais de justiça ou garantias que asseguram direitos fundamentais constitucionalmente estipulados. ${ }^{21}$

Na perspectiva teórica do garantismo ferrajoliano, o Estado de direito em sentido estrito situa ao centro da reflexão jurídica e da projeção política as garantias que salvaguardam os direitos subjetivos, fundando um constitucionalismo jurídico, diverso do constitucionalismo político, próprio da primeira revolução ${ }^{22}$. No próximo item, tratar-se-á de aprofundar a teoria do direito garantista na sua declinação penal, aplicando-o na proteção de entidades juridicas corporificadas nas associações de fins religiosas e entidades religiosas católicas.

$20 / d$.

${ }^{21}$ Id.Ibid., p. 362-363.

22 Trindade, A.-K. (Org.). Garantismo, hermenêutica e (neo)constitucionalismo. Um debate com Luigi Ferrajoli. I parte. Porto Alegre, Livraria do Advogado, 2012a, p. 101. 
Francisco Junior De Oliveira Marques \& Nestor Eduardo Araruna Santiago: O garantismo e a ingerência do Estado na administração dos bens temporais da igreja católica e de associações religiosas: um estudo de caso

\section{DIREITO PENAL GARANTISTA E PROTEÇÃO DAS ASSOCIAÇÕES COM FINS RELIGIOSOS E ENTIDADES RELIGISOSAS CATÓLICAS}

Anteriormente, situou-se a evolução do garantismo e sua nova aplicação no contexto da teoria de Ferrajoli, tratando-se do modelo estatal do garantismo constitucional. Este revelou-se como um novo paradigma que se sustenta no princípio sub lege ou no direito vinculado ao próprio direito, na sua estatura constitucional.

Como já foi dito, o ponto de partida para essa teoria garantista, que tem sua máxima expressão na obra Principia iuris (2011), foi a formulação do direito ferrajoliano penal garantista, ancorado no seu livro, Diritto e Ragione (1989). Ferrajoli desenvolve sua teoria jurídica a partir de duas perspectivas. Em primeiro lugar, é resultado da realidade de luta por direitos na tumultuada Itália da década de 1970. O garantismo de Ferrajoli se gesta in action e, a partir daí, se transforma em teoria. Depois, profundamente relacionada à primeira perspectiva, o paradigma liberal do direito penal mínimo deriva da concepção de sociedade, das relações de poder, das instituições políticas de matriz marxiana ${ }^{23}$.

A partir da abordagem marxiana, as regras jurídicas refletem os interesses econômicos da classe dominante e constituem fatores de instabilidade e reprodução de hierarquia social. Neste ponto, Ferrajoli diverge de Marx, na medida que confronta sua perspectiva de desvalorização do direito e das liberdades individuais. O direito pode converter-se num potente instrumento de emancipação garantista, a ponto de impor-se como lei dos mais frágeis. Ademais, seria paradoxal valorar de burguês as liberdades juridicamente garantidas. Ferrajoli defende o direito à liberdade como um objetivo irrenunciável da luta de classes,

\footnotetext{
${ }^{23}$ Ferrajolli, L., ZOLO, D. Marxismo y cuestión criminal. Em: La questione criminale, n. 1, 1977, p. 61-61.
} 
Francisco Junior De Oliveira Marques \& Nestor Eduardo Araruna Santiago: O garantismo e a ingerência do Estado na administração dos bens temporais da igreja católica e de associações religiosas: um estudo de caso

pois tais direitos sempre foram instrumentos indispensáveis nos conflitos socioeconômicos ${ }^{24}$.

A exigência de liberdade que movia a crítica da legislação e da práxis judiciaria, paralelamente à teorização do garantismo penal, era uma exigência de libertà liberatrice ${ }^{25}$ ou liberdade correlata a uma radical instancia de justiça social. E, essa justiça, em termos do garantismo penal, se realiza pela reafirmação da liberdade iluminista, como descreve Montesquieu, na sua obra l'Esprit des lois, ao afirma: "É, pois, da bondade das leis penais que depende a liberdade do cidadão"26.

Não por menos, a elaboração da teoria de Ferrajoli, sob o fundamento da escola iluminista, foi nomeada de neoiluminismo penal ${ }^{27}$. No discurso iluminista de tutela dos direitos individuais, emerge a necessidade de limitar e controlar o exercício de poder estatal que se inscreve na teoria da soberania da lei, da divisão de poderes e da representação política como um avant-lettre do paradigma do Estado constitucional de direito.

Nesse sentido, o direito penal é o mais adequado locus theoriae para tratar essa relação entre autoridade e direitos subjetivos e, consequentemente, desenhar um paradigma estatal que subordine o poder público à legalidade. Esse paradigma é um sistema de limites e vínculos impostos à legislação e jurisdição penal com o objetivo de restringir o direito e o processo penal em relação a tutela de direitos fundamentais.

A atividade cognitiva é o traço mais importante da ação estatal que submete o julgador à norma e ao fato, vinculando a lei penal a um conjunto de garantias substanciais e formais como parâmetro de justificação do poder de punir, ao que se convém chamar também de

\footnotetext{
${ }^{24}$ Ferrajoli, L. Esiste una democrazia rappresentativa? Em: FERRAJOLI, L.; ZOLO, D. Democrazia autoritaria e capitalismo maturo. Milano, Feltrinelli, 1978, p. 62.

${ }^{25}$ Garrone, A.-G. Libertà liberatrice. Torino, La Stampa, 1992.

${ }^{26}$ Montesquieu. L'Esprit des lois. 1758, p. 130.

27 Ripoli, M. Diritto e morale: il neoilluminismo penale di Luigi Ferrajoli. Em: Gianformaggio, L. (org.) Le ragioni del garantismo: discutendo con Luigi Ferrajoli. Torino, Giappichelli, 1993.
} 
Francisco Junior De Oliveira Marques \& Nestor Eduardo Araruna Santiago: O garantismo e a ingerência do Estado na administração dos bens temporais da igreja católica e de associações religiosas: um estudo de caso

postulados ou axiomas garantistas. As principias garantias penais substanciais são os princípios da taxatividade, da materialidade e ofensividade, culpabilidade; enquanto, aquelas processuais, fundam-se num sistema coeso, a fim de preservar a liberdade e minimizar o poder estatal ${ }^{28}$. Aqui, o princípio da taxatividade aparece com uma arquitrave que sustenta a atividade cognitivo-normativa do garantismo penal. De fato, a jurisdição sustentada nesse princípio limita-se a ser ius dicere, ou afirmação da lei como subsunção dos fatos às normas legislativas e constitucionais ${ }^{29}$.

Os postulados garantistas promovem razoabilidade, proporcionalidade e justiça social. Com o princípio da ofensividade, o Estado é limitado a punir apenas atos penalmente relevantes que ofendem a esfera jurídica de outros. No caso da materialidade, apenas as ações externas podem promover dano a outrem, afastando a pretensão do Estado de punir moções interiores e preservando a intimidade subjetiva. Finalmente, com o princípio da culpabilidade, o que está sob o poder estatal é apenas a responsabilidade subjetiva do indivíduo, excluindo do horizonte do direito penal a responsabilidade objetiva ou sem culpa 30.

Essas garantias são fundamentais para vincular as normas legais aos atos criminosos, tratando de atribuir as penas segundo a culpa do indivíduo e ao sistema legal préestabelecido. As garantias, na teoria do direito penal mínimo, servem para assegurar a cognitividade do processo, afastando o poder arbitrário em todos as fases da aplicação do direito penal. Nesse sentido, o garantismo é um sistema de direitos concretos e não formalismo ingênuo ou legalismo ético. A legalidade aqui pode ser entendida como um delicado jogo de antídotos contra a violência, pronta para transformar-se no seu veneno, na medida que não se respeita os cânones da própria legalidade.

\footnotetext{
${ }^{28}$ Ippolito, D. Itinerari del garantismo. Op. Cit., pp. 59-60.

${ }^{29}$ Id. Ibid., p. 60.

${ }^{30}$ Id. Ibid., pp. 60-61.
} 
Francisco Junior De Oliveira Marques \& Nestor Eduardo Araruna Santiago: O garantismo e a ingerência do Estado na administração dos bens temporais da igreja católica e de associações religiosas: um estudo de caso

Estrita legalidade significa, portanto, que não basta a simples previsão legislativa para definir o crime e a pena (mera legalidade), mas é necessário que à própria lei corresponda a todas as outras garantias que Ferrajoli determina nos dez axiomas do sistema garantista. Nos dois primeiros são individuados a mera legalidade (nulla poena, nulla crimen sine lege) e os oitos seguintes define-se a estrita legalidade (nulla lex poenalis sine necessitate, sine iniuria, sine actione, sine culpa, sine iudicio, sine accusatione, sine probatione, sine defensione) $)^{31}$. Nesse complexo de princípios axiomáticos resulta que, enquanto num sistema da mera legailidade a existência da lei é um critério condicionante, no caso da estrita legalidade é a própria lei que deve ser condicionada ${ }^{32}$.

As associações com fins religiosos e organizações religiosas, por sua vez, como pessoas jurídicas, não estão ilesas de comportamentos desviantes de sua vocação associativa original, beneficiando de forma ilegal suas estruturas organizacionais, bem como seus representes e/ou órgãos colegiados. Na investigação internacional da Columbia Journalism Investigation (CJI) e o Organized crime and corrupton reporting project (OCCRP) sugeriu-se que há uma conexão entre igrejas e ou líderes religiosos em atividades financeiras ilícitas. A base de dados da pesquisa relaciona a lavagem de dinheiro e outros delitos subjacentes com grupos religiosos na América que abusam da confiança dos fiéis ao usarem os espaços de culto para esconder crimes mediante a prática de organização criminosa ${ }^{33}$.

Todo esse contexto criminal exige do direito penal a defesa de bens jurídicos feridos por pessoas jurídicas e seus representantes, visto que tais crimes beneficiam a expansão da organização e, ao mesmo tempo, enriquecem de forma ilícita seus fundadores/lideres e coniventes. Exatamente aqui pode-se falar de responsabilidade direta do Estado, e suas instituições penas, de velar para que os valores depositados nas inistituicoes publicas ou privadas sejam direcionadas aos seus fins predeterminados pelos seus estatutos.

\footnotetext{
${ }^{31}$ Ferrajoli, L. Diretio e Razão. Teoria do garantismo penal. 4ạ. Ed. São Paulo, RT, 2014, p. 91.

32 Resta, E. Per uma teoria generale dei diritti. Em: Scienza \& Politica, v. 2, n. 4, 1990, p. 34-35.

${ }^{33}$ CLIP. Centro Latinoamericano de Investigación Periodistico. Paraíso de dinero y fe. 16 ago. 2020.
} 
Francisco Junior De Oliveira Marques \& Nestor Eduardo Araruna Santiago: O garantismo e a ingerência do Estado na administração dos bens temporais da igreja católica e de associações religiosas: um estudo de caso

Contudo, como toda aplicação do poder punitivo, ao lado da importância da persecução criminal e a legitima aplicação de penas, deve-se ter em conta a cognitividade do processo e a aplicação de um direito penal que assegure mínima e eficientemente os axiomas ferrajolianos da taxatividade, da materialidade, da ofensividade e da culpabilidade.

A jurisprudência dos tribunais que enfrentaram a questão do uso de entidades ou associações religiosas para fins ilegais, ainda que respeitando as garantias fundamentais das entidades, não deixaram de aplicar as punições necessárias. Em Utah, altos lideres de um ramo mómon foram sentenciados por fraude ao erário público mediante lavagem de dinheiro ${ }^{34}$. Noutro caso, agora no Supremo Tribunal Federal, o ministro Edson Fachin, julgando um Habeas Corpus para os lideres da igreja renascer, rejeita o pedido e avalia todos os passos para configuração da lavagem de dinheiro. Garantindo a cognicidade procusual, o ministro relaciona os fatos com o texto legal, a fim de assegurar os princípios constitucionais do dirieto penal e preservar as garantias fundamentais e aplica as penalidades conforme a legalidade ${ }^{35}$.

Ainda em outro Habeas Corpus, impetrado para libertar os lideres de determinada igreja denunciados por delitos de organização criminosa voltada à prática de estelionato ${ }^{36}$, o ministro validou as suspeitas nas quais os criminosos valeram-se da estrutura de entidade religiosa e de empresas vinculadas para arrancar grande valores em dinheiro, lubridiando os fieis mediante fraudes, desviando os numerários oferecidos para determinadas finalidades ligadas à igreja em proveito próprio e de terceiros, além de lucrar na condução das diversas empresas, desvintuando as atividades eminentemente assistenciais e aplicando seguindos golpes.

Nos três exemplos acima, os Tribunais tratam de se manter nos limites da legalidade, especialmente avaliando e julgando conforme os princípios e garantias fundamentais para preservar direitos subjetivos e organizacionais. No próximo item, serão analisadas

\footnotetext{
${ }^{34}$ United States District Court, District of Utah, Central division (2019). Case no. 2:18-CR-365-JNP-BCW, p. 15.

${ }^{35}$ Supremo Tribunal Federal. Habeas Corpus n. 9600 São Paulo. Min. Marcos Aurélio.

${ }^{36}$ Supremo Tribunal Federal. Habeas Corpus n. 153.506 São Paulo. Min. Relator Edson Fachin.
} 
Francisco Junior De Oliveira Marques \& Nestor Eduardo Araruna Santiago: O garantismo e a ingerência do Estado na administração dos bens temporais da igreja católica e de associações religiosas: um estudo de caso

investigações conduzidas pelo MPGO contra uma entidade religiosa e uma associação de fins religiosos, de modo a avaliar se a atividade ministerial esteve em concordâncias com os moldes garantistas penais.

\section{ATUAÇÃO ESTATAL NAS OPERAÇÕES CAIFÁS E VENDILHÕES: UMA AÇÃO EXOBITANTE OU ACERTADA NOS TERMOS DOS CANONES GARANTISTAS}

O estudo de casos tem como referência duas operações realizadas pelo Grupo de Atuação Especial de Repressão ao Crime Organizado (GAECO) do MPGO, denominadas Caifás e Vendilhões. A primeira, em referência ao sumo sacerdote do Templo de Jerusalém no tempo de Jesus (Mt 26,3) e, a segunda, pertinente ao relato da expulsão de comerciantes do Templo de Jerusalém por Jesus (Mc 11, 15-19). Os dois nomes pelos quais o MPGO designa as operações evidenciam que se tratam de questões envolvendo entidades religiosas ou associações para fins religiosos.

Inicialmente, é importante esclarecer do que se trata quando se fala de operações investigatórias do Ministério Público, na sua atividade precípua de oferecer denúncia em vista da ação penal. A investigação criminal antecede à fase processual e tem como objetivo preparar a ação penal, mediante busca de elementos de informação e reconstrução dos fatos delituosos, sem descurar dos direitos e garantias dos investigados.

O corporate crime ganhou grande relevância no final do sec. XX e, mais que nunca, exige um modelo de investigação criminal que alcance os objetivos almejados, em razão de sua complexidade. ${ }^{37}$ A legislação penal brasileira tem tratado de oferecer uma reposta à

\footnotetext{
${ }^{37}$ Menguini, G. Responsabilidade penal da pessoa jurídica. Um estudo comparado. Em: Revista dos Tribunais, v. 961,2015, p. 4.
} 
Francisco Junior De Oliveira Marques \& Nestor Eduardo Araruna Santiago: O garantismo e a ingerência do Estado na administração dos bens temporais da igreja católica e de associações religiosas: um estudo de caso

criminalidade organizada, tipificando novos crimes, acentuando penas e impondo maior rigor na punição.

As atividades investigatórias e a função de movimentar uma ação penal são típicas atividades relacionadas ao poder punitivo do Estado. Paralelo a estas, o Estado constitucional de direitos assegura garantias materiais e processuais fundamentais para a aplicação racional de sua força punitiva. Aqui, se estabelece a relação necessária entre o garantismo e o procedimento investigatório, pois a investigação prévia não tem a função de comprovação da infração penal ou confirmar a tese de acusação de uma denúncia, mas verificar a plausibilidade da imputação, e assim, evitar processos desnecessários ${ }^{38}$. Carneluti, por sua vez, afirma que a investigação criminal, mais do que comprovar um delito, tem o objetivo de excluir imputações descabidas e aventureiras ${ }^{39}$.

Seguindo os preceitos garantistas, o Ministério Público, ao iniciar um procedimento investigatório, deve dar fundamento legal a ela e assegurar todos os direitos e garantias penais cabíveis neste momento pré-processual. Sob esta perspectiva deve ser feita a análise para avaliar se a atividade do MPGO exorbitou de seus poderes nos casos estudados

A operação Caifás foi deflagrada pelo MPGO em 19 de março de 2018 e investiga 11 pessoas por desvios dos cofres da Diocese de Formosa, entidade eclesiástica de direito público canônico e de direito privado estatal, sendo indicado como chefe do esquema Dom José Ronaldo Ribeiro, ordinário da Diocese. A Operação alega que a suposta organização criminosa desviava valores advindos de dízimos, doações e taxas diversas ${ }^{40}$. A denúncia foi apresentada e fundada nos seguintes dispositivos legais do Código Penal: art. 168, § 1, III (apropriação indébita), art. 288 (associação criminosa) e 299 (falsidade ideológica).

\footnotetext{
38 Perazzoni, R. O delegado de polícia no sistema judiciário brasileiro. Das origens inquisitoriais ao garantismo penal de Ferrajoli. Em: Segurança Publica e Cidadania, Brasília, v. 4, n. 2, 2011, p. 100.

${ }^{39}$ Carnelutti, F. Direito Processual Penal. Vol. 2. Campinas, Peritas, 2001, p. 113.

${ }^{40}$ Cavicchioli, G. Ladrões de batina. Em: Istoé, 23 mar. 2018.
} 
Francisco Junior De Oliveira Marques \& Nestor Eduardo Araruna Santiago: O garantismo e a ingerência do Estado na administração dos bens temporais da igreja católica e de associações religiosas: um estudo de caso

Frente a tais acusações levantadas pela Operação Caifás, pode-se perguntar se o MPGO se pautou em fundamentos legais legítimos, bem como se foram assegurados os princípios constitucionais do Estado constitucional de direito, relacionados à teoria do garantismo penal. Para responder estas questões é necessário entender o que seria uma diocese e quais os limites da legislação estatal dada pelo próprio direito.

Uma diocese é uma pessoa jurídica de direito público canônico, ipse iure, nos termos do Codex luris Canoni $(\mathrm{ClC})$, can. $373 \mathrm{ClC} / 83$. Recebe reconhecimento do direito estatal a partir do Codigo Civil, designando-a pessoa juridica de direito privado (art. 44, I CIC;02) e do Acordo Brasil-Santa Sé ou Decreto n. 7.107/2010, art. 3‥, que afirma a personalidade jurídica da Igreja Católica e de suas entidades conforme o Código de Direito Canônico. Por princípio constitucional, como leciona o Ministro Celso de Mello, nos âmbitos dessas entidades haverá sempre uma demarcação de domínios próprios de atuação e de incidência de poderes civil ou estatal, afastando todo tipo de ingerência do Estado em questões interna corporis ${ }^{41}$. Portanto, como pessoa jurídica de direito canônico público e reconhecimento estatal, uma diocese veda todo tipo de ingerência do Estado, observando sempre o sistema constitucional brasileiro.

Dessa autonomia assegurada pela natureza jurídica da Igreja Católica e reconhecida pelo Estado, entende-se a proteção jurídica dos bens eclesiásticos, inscritos nos cann. 12541310 do ClC/83, que regula aquisições, administração, contratos e alienações destes bens. Neste ordenamento jurídico, o Romano Pontífice é o administrador supremo (can. 1256 CIC/88) e, ao bispo, cabe supervisionar a administração dos bens da diocese como pessoa jurídica publica canônica (can. 1276 § 1), sob a égide do direito canônico e da legislação infracanônica por ele mesmo emanada (can. 1276 § 1).

\footnotetext{
${ }^{41}$ Supremo Tribunal Federal. ADIN 4.439 impetrada pela Procuradoria Geral da República. Voto min. Celso de Mello.
} 
Francisco Junior De Oliveira Marques \& Nestor Eduardo Araruna Santiago: O garantismo e a ingerência do Estado na administração dos bens temporais da igreja católica e de associações religiosas: um estudo de caso

Os ilícitos canônicos (can. 1311 CIC/83), sem conexão com o direito estatal, devem ser investigados e punidos pelo direito penal canônico, seja de forma administrativa ou judicial. ${ }^{42}$ No caso em tela, se confirmado, por investigação canônica, dada início em 10 de março de 2018, a pena se inscreve no art. 1, § 1 do Motu Proprio "Como uma mãe amorosa", de demissão do bispo por causar dano ao patrimônio da diocese.

Dialogando com as acusações do MPGO, a apropriação indébita em razão do aumento de despesa e compra de fazenda de gado, apontam para aquisição de dita fazendo por meio de recurso de herança e o aumento de despesa da casa episcopal em razão de acolhimento de dependentes químicos ${ }^{43}$. Com relação ao desvio de dinheiro, importante notar que para o Estado a entidade é privada, os recursos não são públicos, e a legislação garante que a apuração de ilícitos, neste contexto, seja apurada pelo ordenamento canônico. Daqui, decorrem ser desproporcionais as acusações de organização criminosa e falsidade ideológica e, consequentemente, o modus operandi do MPGO mediante o argumento da mera supeita sem a devida contextualização dos fatos.

Na Operação Califas, conclui-se que faltou ao MPGO os cuidados básicos de respeito a garantias constitucionais, descuidando-se da natureza da instituição e da sua competência para lidar com possíveis ilícitos canônicos. Pelo menos dois princípios constitucionais garantistas foram feridos. Primeiro o princípio da taxatividade, visto que os agentes públicos não consideram os dispositivos legais que configuram o estatuto jurídico de uma entidade eclesiástica e sua administração patrimonial. O segundo é da ofensividade, pois, os dízimos e doações são bens tutelados pelo direito canônico, não havendo tutela para essa matéria no direito penal pátrio. O Estado, por meio de seus agentes, deve atuar nos limites da lei, sendo a própria lei regulada pelos princípios garantistas constitucionais, com o perigo, se atuar de forma diversa, de ferir a liberdade e segurança dos cidadãos e suas instituições.

\footnotetext{
42 Orsi, J.-C. Direito Penal Canônico. São Paulo, LTr, 2009, p. 27.

43 Mayrink, J.-M. Igreja reage a acusações de desvios e sai em defesa de bispo em Goiás. Em: Estadão, 16 abr. 2018.
} 
Francisco Junior De Oliveira Marques \& Nestor Eduardo Araruna Santiago: O garantismo e a ingerência do Estado na administração dos bens temporais da igreja católica e de associações religiosas: um estudo de caso

Outro caso trazido ao presente estudo é a Operação Vendilhões, também do MPGO. Deflagrada em 21 de agosto de 2020, o procedimento investigatório contra a Associação do Pai Eterno (AFIPE) aponta a liderança do padre Robson Pereira nos possíveis crimes de apropriação indébita, lavagem de dinheiro, falsificação de documentos, sonegação fiscal e associação criminosa. Como no caso anterior, os recursos da AFIPE advêm de doações.

Em primeiro lugar, é fundamental entender do que se trata ao se falar de associação, afinal, a verificação dos crimes exigem a correta caracterização dos sujeitos envolvidos e dos elementos descritos na tipificação legal. As associações são constituídas pela união de pessoas que se organizam para fina não econômicos (art. 53 CC/02) e são criadas pelo Estado, como pessoas jurídicas de direito privado, conforme determinação legal. As finalidades são múltiplas, ou seja, culturais, sociais, religiosas, dentre outras ${ }^{44}$. 0 texto constitucional brasileiro faz notar que se pode permitir todo tipo de associação, desde que não sejam para fins ilícitos ou paramilitares (art. 50, inciso XVI)

Para a criação de uma associação, o legislador impõe algumas condições que devem constar em seus estatutos (art. 54, incisos I a VII do Código Civil). Os estatutos são uma espécie de lei orgânica dessas entidades e definem os objetivos e a forma de sustentá-las, que pode ser, mediante atividades de natureza comercial, prestação de serviços e doações.

A exigência fundamental é que os recursos estejam vinculados ao objetivos sociais. A Lei n. 9.790/99 estabelece termos de parceria com o poder público, mediante a constituição de Organizações Sociais de Interesse Público (OSCIP). Os termos de parceria devem guardar correspondência com os objetivos sociais da associação. Nesse sentido, a AFIPE é uma associação, e não uma entidade religiosa. Daqui se percebe que o MPGO se equivoca em não fazer a devida distinção no que toca à personalidade jurídica, condição básica para verificação de possíveis ilícitos nessa seara.

${ }^{44}$ Diniz, M.-H. Curso de Direito Civil Brasileiro. Vol I. Teoria Geral do Direito Civil. 29o Ed. São Paulo, Saraiva, 2012. 
Francisco Junior De Oliveira Marques \& Nestor Eduardo Araruna Santiago: O garantismo e a ingerência do Estado na administração dos bens temporais da igreja católica e de associações religiosas: um estudo de caso

Para além do equívoco na correta classificação do sujeito ativo, verifica-se também a dificuldade na compreensão da natureza juridica das fontes de sustento de uma entidade religiosa e de uma associação. Em notícia da Folhaz (2020), informa-se que o MPGO investiga recursos de doações e dízimos. Contudo, a característica jurídica de um dízimo só pode ser aplicada a uma entidade religiosa e, especificamente, a uma pessoa pública canônica denominada diocese ou paroquia. Não existe dízimo para associações civis.

O aparente desconhecimento de Direito Eclesiástico por parte do MPGO, por vezes, pode levar ao uso arbitrário da lei penal, ferindo os princípios do Estado Constitucional de Direito e, por conseguinte, os postulados garantistas. Neste sentido, a 1ạ Câmara Criminal do Tribunal de Justiça de Goiás (TJ-GO) decidiu que pelo arquivamento da denúncia contra a AFIPE demonstra o descuido do mesmo MPGO quanto ao direito associativo. Na decisão, seguida por unanimidade pela Corte, o desembargador relator Nicomendes Domingos Borges entendeu que não houve crime de apropriação indébita na aplicação dos recursos da AFIPE. O magistrado ressalta que a destinação de recursos é realizada por obrigação moral e ética, não havendo imposição legal sobre a aplicação de tais recursos. A destinação cabível é realizada segundo o estatuto, como se prevê no direito associativo. A AFIPE é uma entidade privada, composta por 10 membros e todos estiveram de acordo com relação à destinação dos recursos, não havendo irregularidade cometida no âmbito da instituição. 0 desembargador reconhece o poder de fiscalização do MPGO em associações privadas, contudo, conforme determinação legal, deve ser feita de forma pontual e específica, no caso de notícia de irregularidades ${ }^{45}$.

De fato, na decisão do TJ-GO que concedeu o Habeas Corpus, contra o qual o MPGO se insurgiu, reconheceu-se a atipicidade das condutas em tese praticacdas pelos investigadores. Isso porque a froma como a Afipe é gerida e o destino dado aos valores por ela arrecadatos é assunto interno da entidade e não da ensejo a persecusao criminal.

\footnotetext{
45 Tribunal de Justiça de Goiais. Habeas Corpus n. 544815387.2020.8.09.0000 Goias. Des. Relator Nicomedes Borges.
} 
Francisco Junior De Oliveira Marques \& Nestor Eduardo Araruna Santiago: O garantismo e a ingerência do Estado na administração dos bens temporais da igreja católica e de associações religiosas: um estudo de caso

Nesse caso, observa-se que houve ingerência do Estado mediante atividades investigatórias do MPGO. Descuidou-se, sobretudo, das previsões legais e dos princípios básicos garantistas do Estado de direito, trazendo danos difíceis de reparar à imagem das instituições e das pessoas envolvidas. Como dito acima, o MP tem o papel de velar pelo bom funcionamento das instituições, afastando mediante a persecusao criminal todo tipe de crime tipificado segundo a legalidade e as garantias constitucionais. Contudo, sua função não pode exorbitar do devido processo legal e dos limites próprios dados pela Estado de direito em sentido estrito.

Como no caso da Operação Vendilhões, a ação do MPGO é dirigida somente por um descuidado e violento desejo punitivo. A desproporcionalidade dos atos praticados é claramente constatável na decisão judicial, que reafirma lições simples da relação entre os crimes e possibilidade real dos sujetos de cometê-los. Nesse sentido, a ação do MPGO fere cânones fundamentais garantistas da penas sem culpa ou acusação (nulla lex poenalis sine culpa, sine accusatione), pois, no caso presente, quem teria legitimidade ativa para acusar a associação seriam seus membros ou aqueles que fizeram doações.

\section{CONCLUSÕES}

A evolução conceitual do garantismo conduziu a presente pesquisa em três direções. Numa primeira perspectiva social, o garantismo significou a responsabilidade do Estado comprometer-se com aqueles mais necessitados e, consequentemente, construir uma sociedade fraternas. No segundo momento, com a influência da filosofia iluminista, o garantismo tornou-se um instrumento de proteção do indivíduos frente ao poder punitivo do Estado. Finalmente, na ulterior e contemporânea elaboração do conceito, o garantismo foi assumido na pesquisa e prática de Luigi Ferrajoli. 
Francisco Junior De Oliveira Marques \& Nestor Eduardo Araruna Santiago: O garantismo e a ingerência do Estado na administração dos bens temporais da igreja católica e de associações religiosas: um estudo de caso

Na abordagem ferrajoliana, dá-se a passagem do Estado legal para o Estado constitucional de direito. O garantismo torna-se instrumento de limites para o próprio direito, e a Constituição, o conteúdo normativo pelo qual se controla toda formalidade legal e sua aplicação. Portanto, a teoria do direito garantista de Ferrajoli é uma ampla leitura juspolítica do Estado que repropõe as bases da própria democracia.

Exatamente dessa base global que se pode falar de direito penal garantista. Como parte da teoria de Ferrajali, ainda que se tenha tornado um paradigma e ponto de partida, o direito penal mínimo é uma forma de pensar o poder punitivo estatal dentro de uma racionalidade que o limita, em vista da proteção de direitos individuais e coletivos.

Portanto, tão importante quanto o direito penal que restabelece a verdade e imprime na sociedade o sentimento de não impunidade, tem-se o garantismo como controle da intervenção estatal a partir dos direitos fundamentais constitucionais. Aqui, situa-se o ponto central da presente pesquisa, ou seja, a análise da ingerência do Estado na administração dos bens temporais de associações civis com fins religiosos e entidades religiosas católicas à luz de uma visão garantista penal, mediante estudo das operações do MPGO na Diocese de Formosa e na Afipe.

No percurso da investigação pode-se elencar os seguintes resultados:

1. A evolução conceitual do termo garantismo revela um certa conectividade na preocupação social e na defesa dos mais vulneráveis.

2. Sejam aos indivíduos como os sujeitos coletivos, ambos sujeitos ativos de crimes e, portanto, submetidos ao direito penal, devem-se assegurar-lhes direitos fundamentais inscritos pela teoria garantista penal de Ferrajoli.

3. O percurso realizado na pesquisa deixa claro o pouco conhecimento dos agentes públicos quanto as entidades religiosas e associações que, por sua vez, prejudicou 
Francisco Junior De Oliveira Marques \& Nestor Eduardo Araruna Santiago: O garantismo e a ingerência do Estado na administração dos bens temporais da igreja católica e de associações religiosas: um estudo de caso

o procedimento investigatório do MPGO e feriu garantias constitucionais de proteção das entidades e sujeitos envolvidos.

4. Em razão de equívocos e imprecisões do MPGO, foi imposto uma atividade punitiva autoritária e descuidada dos princípios garantistas para proteção das instituições e seus representantes.

5. Deve-se reafirmar a importância do papel do MP de velar para as instuições não sejam usadas como instrumentos de crimes, contudo, essa missão não torna o MP uma organização acima da lei, do processo e dos princípios garantistas constucionais.

6. A relação de respeito mutuo entre as instuicoes deve preservar o direito próprio das entidades religiosas também realizar sua própria persecusão criminal nos limites dados pelo Estado constitucional de direito.

Os resultados obtidos levam a concluir que o Estado não respeitou as garantias fundamentais das entidades, lesando acordos internacionais, princípios constitucionais e o ordenamento jurídico estatutário.

\section{REFERÊNCIAS BIBLIOGRÁFICAS}

- Brasil. Constituição (1988). Constituição da República Federativa do Brasil. Brasília, DF: Senado Federal: Centro Gráfico, 1988.

- $\quad$ Brasil. Decreto-Lei 2.848, de 07 de dezembro de 1940. Código Penal. Diário Oficial da União, Rio de Janeiro, 31 dez. 1940.

- Brasil. Decreto-Lei 7107, de 11 de fevereiro de 2010. DOU 12.2.2020. Disponivel: http://www.planalto.gov.br/ccivil_03/_ato2007-2010/2010/decreto/d7107.htm. Acessado: 17 out. 2020.

- Brasil. Lei n. 9.605, 12 de fevereiro de 1998. DOU 13.2.1998. Disponível: http://www.planalto.gov.br/ccivil_03/leis/19605.htm. Acessado: 17 out. 2020. 
Francisco Junior De Oliveira Marques \& Nestor Eduardo Araruna Santiago: O garantismo e a ingerência do Estado na administração dos bens temporais da igreja católica e de associações religiosas: um estudo de caso

- Brasil. Lei n. 9790, 23 de março de 1999. DOU 24.3.199. Disponível: http://www.planalto.gov.br/ccivil_03/leis/19790.htm. Acessado: 17 out. 2020.

- Brasil. Supremo Tribunal Federal. Habeas Corpus n. 153.506 São Paulo. Min. Edson Fachin. Disponível em: file://C:/Users/sssma/Desktop/garantismo\%20rev/fachin-hc-exbispos-lavagem-dinheiro.pdf. Acessado em: 13 nov. 2020.

- Brasil. Supremo Tribunal Federal. Habeas Corpus n. 9600 São Paulo. Min. Marcos Aurélio.

Disponivel

em: http://www.stf.jus.br/arquivo/cms/noticiaNoticiaStf/anexo/ADI4439AM.pdf.. Acessado 13 nov. 2020.

- $\quad$ Brasil. Supremo Tribunal Federal. ADIN 4.439 impetrada pela Procuradoria Geral da República. Voto Min. Celso de Mello.. Disponivel em: https://stf.jusbrasil.com.br/jurisprudencia/24807847/habeas-corpus-hc-96007-spstf/inteiro-teor-112281150\#: :text=HC\%2096.007\%20\%2F\%20SP,Por\%20fim\%2C\%20a\&text=Acentua\%20a\%20possibilidade\%20de\%20trancamento,cri me\%20de\%20lavagem\%20de\%20capitais. Acessado 13 nov. 2020.

- $\quad$ Brasil. Tribunal de Justiça de Goiais. Habeas Corpus n. 544815387.2020.8.09.0000 Goias. Des. Relator Nicomedes Borges. Disponível: https://projudi.tjgo.jus.br/PendenciaPublica. Acessado: 13 nov. 2020.

- $\quad$ Broblio, C.-M. Bobbio e Matteucci su constituzionalismo e positivismo giuridico. Con una lettera di Noberto Bobbio a Nicola Mateucci. Materiali Per Una Storia della Cultura Giuridica, a. 30, n. 2, dicen., p. 387-425, 2000.

- $\quad$ Carnelutti, F. Direito Processual Penal. Vol. 2. Campinas, Peritas, 2001.

- Cavicchioli, G. Ladrões de batina. Istoé, 23 mar. 2018. Disponíevel: https://istoe.com.br/ladroes-de-batina. Acessado: 16 out. 2020.

- $\quad$ CLIP. CENTRO LATINOAMERICANO DE INVESTIGACIÓN PERIODISTICO. Paraíso de dinero y fe. 16 ago. 2020. Disponível: https://www.elclip.org/paraisos-de-dinero-y-fe. Acessado: 13 out. 2020

- CÓDIGO DE DIREITO CANÔNICO, promulgado por João Paulo II, Papa. Tradução Conferência Nacional dos Bispos do Brasil. São Paulo: Loyola, 1987. 
Francisco Junior De Oliveira Marques \& Nestor Eduardo Araruna Santiago: O garantismo e a ingerência do Estado na administração dos bens temporais da igreja católica e de associações religiosas: um estudo de caso

- De Ruggiero, G. Historia del liberalismo europeo. Albolte, Editorial Comares, 2005

- Dliniz, M.-H. Curso de Direito Civil Brasileiro. Vol I: Teoria Geral do Direito Civil. 29 e Ed. São Paulo, Saraiva, 2012

- Ferrajoli, L. Diretio e Razão. Teoria do garantismo penal. 4ạ. Ed. São Paulo, RT, 2014.

- Ferrajoli, L. Principia iuris. Teoria del derecho y de la democracia. Madrid, Seps, 2011.

- Ferrajoli, L. Diritto fundamentali. Um dibattito teórico. 3ạ. Ed. Roma-Bari, Laterza, 2008.

- Ferrajoli, I. Lo Stato di diritto tra passato e futuro. COSTA, P; ZOLO, D. (a cura di). Lo Stato di diritto. Storia, teoria, critica. Milano, Feltrinelli, p. 349-386, 2003.

- FERRERA, M. II modelo sud-europeo di walfare state. Revista Italiana de Scienza Política, v. 36, n. 1, apr., p. 67-101, 1996.

- Ferrajoli, L. Esiste una democrazia rappresentativa? FERRAJOLI, L.; ZOLO, D. Democrazia autoritaria e capitalismo maturo. Milano, Feltrinelli, 1978.

- Ferrajoli, L.; ZOLO, D. Marxismo y cuestión criminal. La question criminales, n. 1, 1977, p. 59-91.

- Folhaz. Operação do ministério público apura irregularidade na Afipe. 21 ago. 2020. Disponível: https://www.folhaz.com.br/noticias/operacao-mp-afipe. Acessado: 16 out. 2020

- Fourier, C. Le nouveau monde industriel et sociétaire. 1829. Disponível: https://inventin.lautre.net/livres/Fourier-Nouveau-monde.pdf. Acessado: 06 out. 2020.

- Francisco, Papa. Carta Apostolica Motu Proprio Mater Amabilis. Vaticano, 2016. Disponível: http://www.vatican.va/content/francesco/pt/apost_letters/documents/papafrancesco-lettera-ap_20160815_sedula-mater.html. Acessado: 06 out. 2020.

- Garrone, A.-G. Libertà liberatrice. Torino, La Stampa, 1992.

- $\quad$ Ippolito, D. Itinerari del garantismo. Videre, a. 3, n. 6, jul.-dez., p. 53-67, 2011.

- Jouvencel, P. Droit du vivre de la proprieté e du garantisme. Paris, Paul Masgana, 1847.

- Mayrink, J.-M. Igreja reage a acusações de desvios e sai em defesa de bispo em Goiás. Estadão, 16 abr. 2018. Disponível: https://brasil.estadao.com.br/noticias/geral,igreja- 
Francisco Junior De Oliveira Marques \& Nestor Eduardo Araruna Santiago: O garantismo e a ingerência do Estado na administração dos bens temporais da igreja católica e de associações religiosas: um estudo de caso

reage-a-acusacoes-de-desvios-e-sai-em-defesa-de-bispo-preso-em-goias,70002271007 Acessado: 17 out. 2020.

- $\quad$ Mello, C. Voto do Ministro Celso de Mello na ADIN 4.439 impetrada pela Procuradoria Geral da República. Disponível em: https://luisrobertobarroso.com.br/wpcontent/uploads/2017/08/ADI-4439-vers\%C3\%A3o-final.pdf. Acesso em: 02 jul. 2018.

- Menghin, G. Responsabilidade penal da pessoa jurídica. Um estudo comparado. Revista dos Tribunais, v. 961, nov. p. 1-20, 2015.

- Montesquieu. L’Esprit des lois. 1758. Disponível: http://archives.ecolealsacienne.org/CDI/pdf/1400/14055_MONT.pdf. Acessado: 06 out. 2020.

- Orsi, J.-C. Direito Penal Canônico. São Paulo, LTr, 2009.

- $\quad$ Pagano, M. Considerazioni sul processo criminale. Napoli, Tosi y Nobile, 1801.

- Perazzoni, R. O delegado de polícia no sistema judiciário brasileiro. Das origens inquisitoriais ao garantismo penal de Ferrajoli. Segurança Publica e Cidadania, Brasília, v. 4, n. 2, p. 77-110, jul./dez., 2011.

- Pisarello, G., Suriano, R. Entrevista a Luigi Ferrajoli. Isonomía. Em: Revista de Teoría e Filosofia del Derecho, n. 9, 1998, pp. 187-192.

- Resta, E. Per uma teoria generale dei diritti. Scienza \& Politica, v. 2, n. 4, p. 31-43, 1990.

- Ripoli, M. Diritto e morale: il neoilluminismo penale di Luigi Ferrajoli. Gianformaggio, L. (org.) Le ragioni del garantismo: discutendo con Luigi Ferrajoli. Torino, Giappichelli, 1993.

- Trindade, A.-K. Revisitando o garantismo de Luigi Ferrajoli. Uma discussão sobre metateoria, teoria do direito e teoria política. Revista Eletronica da Faculdade de Direito de Franca, v. 5, n. 1, p. 3-21, 2012.

- Trindade, A.-K. Garantismo versus neoconstitucionalismo. Os desafios do protagonismo judicial em terrae brasilis. Ferrajoli, L.; Streck, L.; Trindade, A.-K. (Org.). Garantismo, hermenêutica e (neo)constitucionalismo. Um debate com Luigi Ferrajoli. I parte. Porto Alegre, Livraria do Advogado, p. 95-131, 2012a.

- US, UTAH, CASE No. 2:18-CR-365-JNP-BCW, 2019.Disponivel em: https://www.justice.gov/opa/press-release/file/1258476/download. Acessado em: 12 
Francisco Junior De Oliveira Marques \& Nestor Eduardo Araruna Santiago: O garantismo e a ingerência do Estado na administração dos bens temporais da igreja católica e de associações religiosas: um estudo de caso

nov. 2020.

- Zaffaroni, E.-R. "La rinascita del diritto penale liberale o la Croce Rossa giudiziaria”. Em: Gianfromaggio, L. (org.) Le ragioni del garantismo: discutendo con Luigi Ferrajoli. Torino, Giappichelli Editore, 1993, p. 383-395. 